\title{
Circulating Cell Free DNA and DNA Integrity Index as Discriminating Tools between Breast Cancer and Benign Breast Disease
}

\author{
Rania Elhelaly ${ }^{1 *}$, Narmen Effat ${ }^{1}$, Mohamed Abd El-Fattah Hegazy ${ }^{2}$, Khaled \\ Abdelwahab $^{2}$, Omar Hamdy ${ }^{2}$, Ekbal M Abo Hashem', Rasha R Elzehery ${ }^{1}$
}

\begin{abstract}
Objectives: Early diagnosis of cancer remains a great challenge in the field of laboratory medicine. We investigated the ability of ccf DNA and DNA integrity index (DNA II) in differentiating benign from malignant breast diseases. Methods: Serum samples were collected from 50 patients with benign breast disease (BBD) and 50 newly diagnosed breast cancer (BC) patients, in addition to 50 control women. VEGF was measured by ELISA, while Real-time q-PCR was used to measure ccf DNA concentrations and to assess the concentrations of ALU repeats, both short fragments (115 bp) and long fragments (247 bp), then DNA II was calculated (all were done before and after radical mastectomy). Results: BC group showed significantly higher ccf DNA concentrations and DNA II compared to BBD and control groups, meanwhile, no statistically significant differences were found between BBD and control groups. Ccf DNA concentrations decreased significantly after surgery $(\mathrm{P}<0.001)$. Good AUC was found for ccf DNA (AUC $=0.860)$, fair AUC was found for DNA II (AUC $=0.727$ ), while VEGF AUC failed to discriminate between BBD and BC cases. Conclusion: ccf DNA and DNA II could be used as excellent molecular biomarkers for early diagnosis of BC and for monitoring the efficiency of therapy in such patients. Utilizing these molecular markers would improve both the healthcare and economic burden of malignancy.
\end{abstract}

Keywords: ccf DNA, DNA integrity index- breast cancer- benign breast disease

Asian Pac J Cancer Prev, 23 (2), 545-552

\section{Introduction}

Cancer is considered the second leading cause of death worldwide (Arko-Boham et al., 2019). Breast cancer (BC) is currently considered the most common cancer and the second cause of cancer-related deaths in women worldwide (Torre et al., 2016). In Egypt; BC is accounting for $32.4 \%$ of all female cancers and $16.4 \%$ of all cancers after liver cancer in both sexes (International Agency for Research on Cancer, 2020). Breast mammography and ultrasound may have the potential to detect BC (Corsetti et al., 2011). Mammography is the gold standard for early detection of $\mathrm{BC}$ and was proven to be the only screening method for BC. However, it may fail to identify patients due to the overlapping dense fibroglandular tissue which reduces the visibility of tumor tissue (Gilbert et al., 2016). Also, these methods have drawbacks such as radiation exposure (Tabár et al., 2011). Serum carcinoembryonic antigen (CEA) and cancer antigen 15-3 (CA 15-3) are two widely used tumor markers. These markers are of limited use in early diagnosis because of restricted specificity and sensitivity (He et al., 2016).

Also, conventional sampling methods such as needle biopsies are subjected to procedural complications and difficulty in obtaining sufficient material of good quality for genomic profiling (reported failure rates range from $<10 \%$ to $>30 \%$ of cases) (VanderLaan et al., 2014). Because of these limitations, it is necessary to develop a new non-invasive diagnostic method for early detection of BC patients.

It was proved that large number of epigenetic and genetic aberrations have a great role in various cancers (Coppedè et al., 2014). Liquid biopsy means detection of nucleic acids originating from different body cells in biological samples as blood, saliva, urine or stool. In case of cancer; circulating tumor cells, circulating cellfree tumor DNA (ccf DNA), microvesicles containing mRNAs, micro RNAs (miRNAs) and proteins, could be measured in peripheral blood or other body fluids using specific techniques (Guerriero et al., 2019).

So, development of new diagnostic methods with higher sensitivity and specificity to detect and early 
diagnose $\mathrm{BC}$ is a critical demand. Hence the role of "liquid biopsy" which would allow repeated samplings and reflecting the characteristics of tumor dynamics (Crowley et al., 2013).

Apoptosis is the main source of ccf DNA in healthy individuals producing evenly sized shorter DNA fragments meanwhile, in malignancy necrosis produces uneven longer DNA fragments in addition to the shorter fragments from apoptosis. Therefore; elevated levels of longer fragments of DNA in the blood have been pointed to the presence of malignant tumor DNA (Fleischhacker and Schmidt, 2017).

These novel biomarkers are thought to have great potential and could provide more detailed individualized decision-making during treatment, including the ability for risk assessment, early cancer detection, and prediction of treatment or disease prognosis. (Sobhani et al., 2018).

Up till now there is no agreement as regard cut off values of ccf DNA or DNA II in diagnosis of BC or their role in follow up of treatment. So, the present study aimed to investigate the possible role of using serum ccf DNA concentration and DNA II for early diagnosis of BC and to differentiate it from $\mathrm{BBD}$, in addition to assess their role in follow up of treatment.

\section{Material and Methods}

This study is a cross sectional observational study conducted on 150 females; 50 newly diagnosed BC patients, 50 cases with BBD and 50 healthy age matched female as a control group. BC patients who previously received chemotherapy/radiotherapy or undergone surgery or those who have other type of malignancy or autoimmune disease were excluded.

Diagnosis of breast cancer was based on mammography, CA 15-3 levels and biopsy. These patients were subjected to radical mastectomy. Cases were selected from Oncology Center, Mansoura University, during the period from January, 2017 to June, 2018. Controls were selected from hospital staff undergoing regular checkup laboratory investigations.

The study protocol was approved by the research ethics committee of Mansoura University, and an informed written consent was obtained from each participant. It included an explanation of the study aim and design. All data was confidential.

\section{Sampling}

Eight $\mathrm{ml}$ fasting venous blood were withdrawn as basal samples (before surgery for $\mathrm{BC}$ patients and before any treatment for BBD patients) for all subjects included in our study $(\mathrm{n}=150)$ under complete aseptic condition, divided into 2 aliquots, $4 \mathrm{ml}$ each, and delivered into plain tubes, left at room temperature for 20 min., centrifuged at 3,000 rpm, separation of serum was done followed by re-centrifugation. One aliquot was used for usual laboratory workup and vascular endothelial growth factor (VEGF). The other serum aliquot was kept frozen at $-80^{\circ} \mathrm{C}$ till performing DNA analysis. Second sample was withdrawn from $50 \mathrm{BC}$ patients 48 hours after radical mastectomy.
We preferred serum samples because serum contains higher concentration than plasma of these markers (Umetani et al., 2006).

\section{Methods}

Measurement of VEGF: it was measured by ELISA kits supplied by Sun Red (Shanghai, China).

Measurement of total circulating cell free DNA (ccf DNA) concentration:

\section{A-Extraction of genomic DNA}

Extraction of genomic DNA was done from patient's serum using serum and body fluid protocol. Genomic DNA Purification Mini Kits were supplied by Thermo Fisher Scientific (168 Third Avenue, Waltham, MAUSA 02451).

\section{$B$ - Real time PCR amplification for measurement of ccf} DNA (Lo et al., 2000)

The primers used were specific for beta globin gene. Primers were purchased as lyophilized reagents (Invetrogen by Life Technologies, USA). Forward primer: 345 F5'-GTGCACCTGACTCCTGAGGAGA-3' $(27.8 \mathrm{nmol})$ and reverse primer: $445 \mathrm{R}^{\prime}$ 'C C T T GATA C C A A C C T GCCCA G-3', (33.7 nmol). A dual-labelled fluorescent TaqMan probe, beta globin-402T, was used 5'-(FAM) AAGGTGAACGTGGATGAAGTTGGTGG-(Tamara)-3' (16.4 nmol). The probe was reconstituted with $164 \mu \mathrm{l}$ of purified sterile water to a final concentration of $100 \mathrm{pmol} /$ $\mu 1$. The total volume of the PCR reaction mixture was $25 \mu 1$ $(1 \mu \mathrm{L}$ of each primer, TaqMan prob $1 \mu \mathrm{L}$, extracted DNA

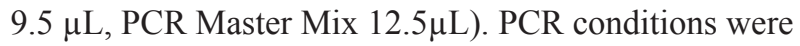
as follow: initial denaturation at $94^{\circ} \mathrm{C}$ for $2 \mathrm{~min}$, then 40 cycles of denaturation $\left(94^{\circ} \mathrm{C}\right.$ for $\left.1 \mathrm{~min}\right)$, annealing $\left(55^{\circ} \mathrm{C}\right.$ for $40 \mathrm{sec})$, and extension $\left(72^{\circ} \mathrm{C}\right.$ for $\left.30 \mathrm{sec}\right)$. Finally, extension for $10 \mathrm{~min}$ at $72^{\circ} \mathrm{C}$ was followed using 7500 Real-Time PCR System (ABI, Abilene, TX, USA).

\section{C-Measurement of ccf DNA integrity index (Umetani et al., 2006)}

Using Real-time ALU-PCR to assess the concentration and integrity index (DNA II) of serum ccf DNA, both short fragments (115 bp) and long fragments (247 bp) from consensus sequence with abundant genomic ALU repeats were amplified and quantified. DNA II was calculated as the ratio of ALU247 / ALU115 fragments.

The sequences of the primers were as follows:

ALU115-forward:

5'-CCTGAGGTCAGGAGTTCGAG-3' and reverse 5'-CCCGAGTAGCTGGGATTACA-3'

ALU247-forward:

5'GTGGCTCACGCCTGTAATC-3' and reverse: 5'CAGGCTGGAGTGCAGTGG-3'.

The reaction mixture for each ALU-qPCR contained $5 \mu \mathrm{L}$ DNA template, $0.5 \mathrm{ml}$ of each forward and reverse primer (ALU115 or ALU247), $10 \mu$ L SYBR Green Master Mix (Rox, Weitefeld, Germany) and $4 \mu \mathrm{L}$ double-distilled water in total reaction volume of $20 \mu \mathrm{L}$. PCR conditions were as follow: initial denaturation at $95^{\circ} \mathrm{C}$ for $10 \mathrm{~min}$, 
followed by 35 cycles of $95^{\circ} \mathrm{C}$ for $15 \mathrm{sec}$, and annealing at $64 \mathrm{oC}$ for $1 \mathrm{~min}$ in 7500 Real-Time PCR System (ABI, Abilene, TX, USA).

The absolute equivalent amount of serum DNA fragments in each sample was determined using standard curve with serial dilutions of human genomic DNA from multiple anonymous donors. Standard curves were created for both ALU115 and ALU247 primer sets by PCR amplifying 10-fold serially diluted human genomic DNA samples.

\section{Statistical analysis}

Results were analyzed using Statistical package for Social Science (IBM Corp. Released 2011. IBM SPSS Statistics for Windows, Version 20.0. Armonk, NY: IBM Corp.). Parametric variables were analyzed by Student T Test for comparison between two study group means. For the comparison of the three groups' means, one-way analysis of variance (ANOVA) was used. Nonparametric variables were analyzed by Mann Whitney Test for comparison between two study groups median. For the comparison of the three groups' medians, The Kruskal-Wallis test was used. Qualitative variables were compared using the $\chi^{2}$ test and Fisher's exact test. Correlations between categorical variables were done by Chi-square coefficient. Receiver operating characteristic (ROC) curve was plotted for diagnostic evaluation of the studied biomarkers. Predictors of BC were determined by Regression analysis: All tests were 2-sided and a $\mathrm{P}$-value $<0.05$ was considered statistically significant.

\section{Results}

As regard demographic data; the present study was conducted on $50 \mathrm{BBD}$ and $50 \mathrm{BC}$, their mean age was $47.6 \pm 12,48.9 \pm 12$ years respectively. In addition to 50 healthy females, their age was $46.4 \pm 7.9$ years. BBD cases were premenopausal (84\%), while 23 out of 50 cases of BC were postmenopausal (53.5\%). Past history of breast disease was significantly associated with BBD when compared to control and $\mathrm{BC}(\mathrm{P}<0.001)$.

\section{Clinicopathological characteristics}

Concerning BBD types; fibroadenoma was the commonest type (52\%), followed by fibroadenosis (10\%), Fibrocystic disease (8\%), Benign phylloid (6\%) Traumatic fat necrosis (4\%), Ductectasia (6\%), Duct papilloma (4\%), Tubular adenoma (4\%) and Cyst (6\%).

As regard pathological types of BC cases; intraductal carcinoma constitutes the commonest pathology (IDC: $88.4 \%$ ), followed by intralobular carcinoma (ILC: $9.3 \%$ ) and ductal carcinoma insitu (DCIS: $2.3 \%$ ). Furthermore; out of $50 \mathrm{BC}$ cases $(2.3 \%)$ were grade I , $(65.1 \%)$ were grade II and (11.6\%) were grade III. $81.4 \%$ of the BC patients had no metastasis, while $18.6 \%$ of them had metastasis.

The current study reported significant higher median ccf DNA concentration ( $\approx 4$ folds increase) in BC cases $(92 \mathrm{ng} / \mathrm{ml})$ in comparison to BBD cases and controls $(23.5$ and $24.8 \mathrm{ng} / \mathrm{ml}$ respectively) $(\mathrm{P}<0.001)$ with no significant difference between BBD cases and controls (Table 1).

Moreover, DNA II showed significant higher median concentration $(\approx 2$ folds increase) in BC cases $(0.44)$ in comparison to BBD cases and controls $(0.24$ and 0.21 respectively) ( $\mathrm{P}<0.001)$ with no significant difference between BBD cases and controls (Table 1).

VEGF showed significantly higher median values in $\mathrm{BBD}$ and $\mathrm{BC}(648.7,611 \mathrm{pg} / \mathrm{ml})$ when compared to controls $(239 \mathrm{pg} / \mathrm{ml})$. However, there was no statistically significant difference between $\mathrm{BBD}$ and $\mathrm{BC}$ groups regarding VEGF (Table 1).

As regard pathological type of $\mathrm{BBD}$; there were no statistical significant difference in serum levels of ccf DNA, DNAII or VEGF.

On the other hand; ccf DNA concentration only showed significant positive correlation with higher tumor grade $(r=0.422$ and $P=0.013)$. Otherwise, no significant correlation was found in ccfDNA, DNAII or VEGF serum

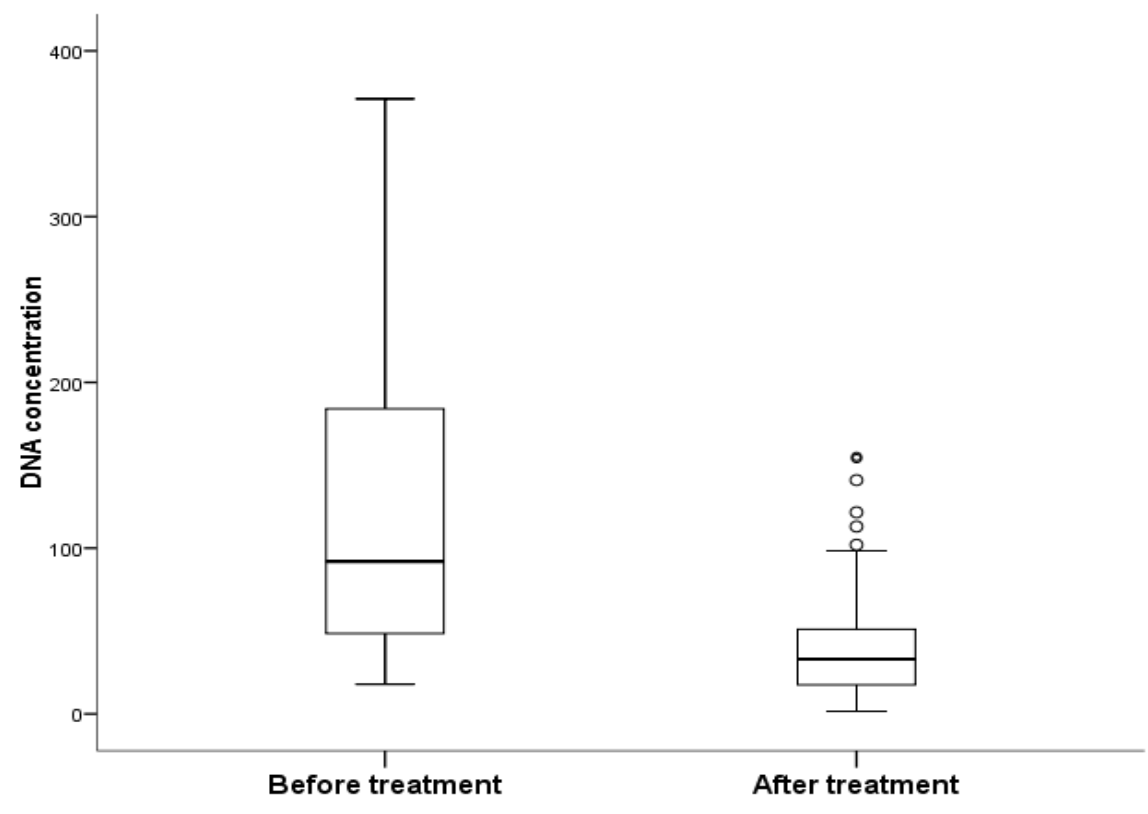

Figure 1. ccf DNA Concentration before and after Surgery in BC Cases. 


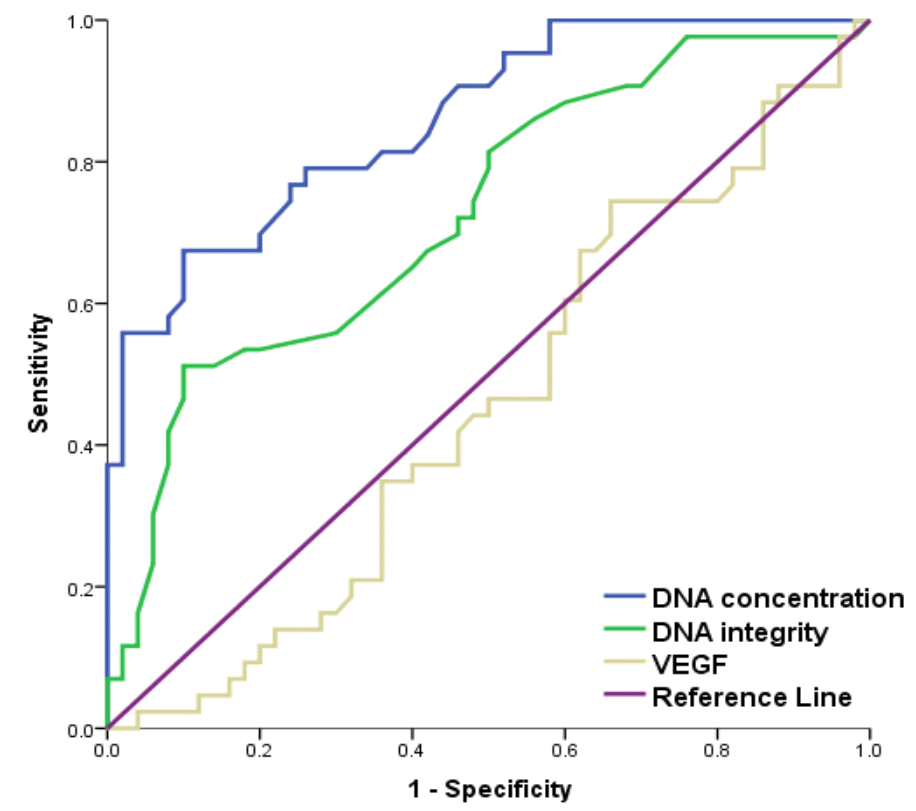

Figure 2. ROCs of ccf DNA Concentration, DNA II and VEGF Levels for Discrimination between BBD and BC Groups.

Table 1. Comparison of Demographic Data, Baseline cef DNA Concentrations, DNA II and VEGF among the Studied Groups

\begin{tabular}{|c|c|c|c|c|c|c|c|c|c|c|c|}
\hline \multirow{2}{*}{$\frac{\text { Parameter }}{\text { Age (years) }}$} & \multirow[b]{2}{*}{ mean $\pm \mathrm{SD}$} & \multicolumn{2}{|c|}{ Control $\mathrm{N}=50$} & \multicolumn{2}{|c|}{$\mathrm{BBD} N=50$} & \multicolumn{2}{|c|}{$\mathrm{BC} \mathrm{N}=50$} & \multirow{2}{*}{$\frac{\mathrm{P} 1}{0.569}$} & \multirow{2}{*}{$\frac{\mathrm{P} 2}{0.603}$} & \multirow{2}{*}{$\frac{\text { P3 }}{0.29}$} & \multirow{2}{*}{$\frac{\mathrm{P} 4}{0.555}$} \\
\hline & & 46.4 & 7.9 & 47.6 & 12 & 48.9 & 12 & & & & \\
\hline Single & $\mathrm{N}, \%$ & 3 & $7.50 \%$ & 5 & $10 \%$ & 1 & $2.30 \%$ & 0.317 & 0.728 & 0.348 & 0.212 \\
\hline Married & $\mathrm{N}, \%$ & 37 & $92.50 \%$ & 45 & $90 \%$ & 42 & $97.70 \%$ & & & & \\
\hline Premenopausal & $\mathrm{N}, \%$ & 26 & $65.00 \%$ & 42 & $84 \%$ & 20 & $46.50 \%$ & 0.001 & 0.037 & 0.09 & $<0.001$ \\
\hline Postmenopausal & $\mathrm{N}, \%$ & 14 & $35.00 \%$ & 8 & $16 \%$ & 23 & $53.50 \%$ & & & & \\
\hline Positive family history & $\mathrm{N}, \%$ & 7 & $17.50 \%$ & 9 & $18 \%$ & 8 & $18.60 \%$ & 0.991 & 0.951 & 0.896 & 0.94 \\
\hline Past history of breast disease & $\mathrm{N}, \%$ & 0 & $0 \%$ & 18 & $36 \%$ & 2 & $4.70 \%$ & $<0.001$ & $<0.001$ & 0.495 & $<0.001$ \\
\hline Hormonal or OCP & $\mathrm{N}, \%$ & - & - & 14 & $28 \%$ & 10 & $23.30 \%$ & 0.414 & - & - & 0.414 \\
\hline ccf DNA conc.(ng/ml) & $\begin{array}{l}\text { Median } \\
\text { range }\end{array}$ & 24.8 & $0.6-68$ & 23.5 & $0.6-105$ & 92 & $17.9-371$ & $<0.001$ & 0.548 & $<0.001$ & $<0.001$ \\
\hline DNA II & $\begin{array}{l}\text { Median } \\
\text { range }\end{array}$ & 0.21 & $0.10-0.40$ & 0.24 & $0.10-0.77$ & 0.44 & $0.10-1.03$ & $<0.001$ & 0.078 & $<0.001$ & $<0.001$ \\
\hline VEGF (pg/ml) & $\begin{array}{l}\text { Median } \\
\text { range }\end{array}$ & 239 & $135.5-330.7$ & 648.7 & $222-2468$ & 611 & $287-2003$ & $<0.001$ & $<0.001$ & $<0.001$ & 0.455 \\
\hline
\end{tabular}

$\mathrm{BBD}$, benign breast disease; $\mathrm{BC}$, breast cancer; $\mathrm{OCP}$, oral contraceptive Pills. P1, comparison between control, BBD, BC; $\mathrm{P} 2$, comparison between control and $\mathrm{BBD} ; \mathrm{P} 3$, comparison between control and $\mathrm{BC}, \mathrm{P} 4$, comparison between $\mathrm{BBD}$ and $\mathrm{BC}$.

levels with $\mathrm{BC}$ stage.

Comparing post radical mastectomy ccf DNA concentrations with basal median values revealed significant reduction of its median value after surgery (33 vs $92 \mathrm{ng} / \mathrm{ml}$ respectively, $\mathrm{P}=<0.001$ ) (Figure 1 ).

To verify validity of ccf DNA concentration and DNA II in discrimination between $\mathrm{BBC}$ and $\mathrm{BC}$ cases; ROC curve was conducted. Ccf DNA concentration and DNAII showed good $(\mathrm{AUC}=0.860)$ and fair $(\mathrm{AUC}=0.727)$ discrimination respectively between $\mathrm{BBD}$ and $\mathrm{BC}$ cases meanwhile, VEGF failed to discriminate $(\mathrm{AUC}=0.545)$. Ccf DNA concentration $\geq 74 \mathrm{ng} / \mathrm{ml}$ and DNAII $\geq 0.44$ were diagnostic of $\mathrm{BC}$ with specificity of $90 \%$ for both and PPV of 85.3 and $81.5 \%$ respectively; but with lower sensitivity (67.4 and $51.2 \%$ respectively). So; ccf DNA concentration showed significantly better discrimination
Table 2. AUCs and Performance Criteria of ccf DNA Concentration, DNA Integrity Index and VEGF Levels for Discrimination between $\mathrm{BBD}$ and $\mathrm{BC}$ Cases

\begin{tabular}{lccc}
\hline Parameter & $\begin{array}{c}\text { ccf DNA } \\
\text { concentration }\end{array}$ & $\begin{array}{c}\text { DNA integrity } \\
\text { index }\end{array}$ & VEGF \\
\hline AUC & 0.86 & 0.727 & 0.545 \\
95\% CI & $0.787-0.932$ & $0.624-0.830$ & $0.428-0.663$ \\
Cut off & 74 & 0.44 & 498 \\
Sensitivity (\%) & 67.4 & 51.2 & 74.4 \\
Specificity (\%) & 90 & 90 & 34 \\
PPV (\%) & 85.3 & 81.5 & 49.2 \\
NPV (\%) & 76.3 & 68.2 & 60.7 \\
P & - & 0.039 & $<0.001$ \\
\hline
\end{tabular}

AUC, area under ROC curve; CI, confidence interval; PPV, positive predictive value; NPV, negative predictive value; $\mathrm{P}$, comparison between AUC of studied markers versus AUC of ccf DNA concentration. 
Table 3. Regression Analysis for Prediction of BC Development

\begin{tabular}{|c|c|c|c|c|c|c|c|c|}
\hline \multirow{3}{*}{$\begin{array}{l}\text { Parameter } \\
\text { Age }\end{array}$} & \multicolumn{4}{|c|}{ Univariable } & \multicolumn{4}{|c|}{ Multivariable } \\
\hline & \multirow{2}{*}{$\frac{\mathrm{p}}{0.586}$} & \multirow{2}{*}{$\frac{\mathrm{OR}}{1.006}$} & \multicolumn{2}{|c|}{$95 \% \mathrm{CI}$} & \multirow[t]{2}{*}{$\mathrm{p}$} & \multirow[t]{2}{*}{ OR } & \multicolumn{2}{|c|}{$95 \% \mathrm{CI}$} \\
\hline & & & 0.985 & 1.028 & & & & \\
\hline Marital status & 0.138 & 2.52 & 0.742 & 8.554 & & & & \\
\hline Postmenopausal & $<0.001$ & 3.034 & 1.704 & 5.4 & 0.004 & 3.209 & 1.449 & 7.11 \\
\hline Positive family history & 0.94 & 1.026 & 0.53 & 1.984 & & & & \\
\hline Hormonal or OCP & 0.602 & 0.856 & 0.476 & 1.537 & & & & \\
\hline Previous BBD & $<0.001$ & 0.238 & 0.107 & 0.531 & 0.035 & 0.286 & 0.09 & 0.915 \\
\hline VEGF & 0.087 & 1.001 & 0.999 & 1.002 & & & & \\
\hline Ccf DNA & & 1.021 & 1.012 & 1.031 & $<0.001$ & 1.02 & 1.009 & 1.031 \\
\hline DNA integrity index & $<0.001$ & 2.555 & 1.745 & 3.742 & 0.046 & 2.904 & 1.88 & 5.157 \\
\hline
\end{tabular}

OR, odds ratio; CI, confidence interval; OCP, oral contraceptive pills; BBD, Benign Breast Disease

between $\mathrm{BBD}$ and $\mathrm{BC}$ cases than that of DNA integrity index $(\mathrm{P}=0.039)$ (Table 2, Figure 2).

Logistic regression analysis was conducted for prediction of $\mathrm{BC}$ development, using age, menopausal status, family history, receiving oral contraceptive pills (OCP), previous breast disease, VEGF, ccf DNA concentration and DNA integrity index as covariates. Postmenopausal status was associated with the highest risk factor for BC development (OR 3.209, 95\% CI: 1.449$7.110, \mathrm{P}=0.004)$. Also; DNA II and ccf DNA concentration were considered risk predictors of $\mathrm{BC}$ development (OR 2.904, 95\% CI: 1.880-5.157, $\mathrm{P}=0.046$ and $\mathrm{OR} 1.020$, 95\% CI: 1.009-1.031, $\mathrm{P}<0.001$ respectively) (Table 3 ).

\section{Discussion}

Early diagnosis of breast cancer is crucial for reducing cancer-related mortality (Lannin and Wang, 2017). Ccf DNA is recognized as a novel biomarker in the diagnosis of many cancers (Yu et al., 2019). There are several methods for detection of ccf DNA in BC such as the concentration of ccf DNA, ccf DNA integrity, microsatellite alteration, gene mutations, DNA methylation. etc (Wang et al., 2017).

This study assessed utility of serum ccf DNA concentrations and DNA II in early diagnosis and follow up of complete removal of $\mathrm{BC}$ following radical mastectomy.

The current study revealed significant higher concentration of cef DNA $(\approx 4$ folds $)$ and DNA II $(\approx 2$ folds) in BC cases when compared to BBD cases and controls. This could be attributed to release of higher concentration of genomic DNA from tumor cells by autophagy and necrosis into the circulation, beside suppressed DNase activity in sera of cancer patients but not in healthy subjects (Stewart and Wild, 2014). Also, the lower DNA integrity in healthy controls and BBD cases probably assigned to low necrotic activity in body tissues (Arko-Boham et al., 2019) and clearing apoptotic and necrotic cells by infiltrating phagocytes (Mouliere et al., 2011), which thereby lowering the concentration of longer DNA fragments in the bloodstream. Meanwhile, there were overlap of ccf DNA concentrations and DNA II between $\mathrm{BBD}$ cases and controls. A possible reason may be that the ccf DNA is discharged from cancer cells and is not found in the hyperplasia samples or in healthy controls (Gong et al., 2012).

Our results are in concordance with the results of Hashad et al., (2012) who reported a statistically significant difference in plasma ccf DNA concentration between the $\mathrm{BC}$ group (42 cases) and both BBD (30 cases) and control $(n=27)$ groups $(P<0.001)$. while no significant difference was found between the control group and BBD group ( $\mathrm{P}=0.23)$. El Edel et al., (2018) using cycle threshold revealed that plasma levels of ccf DNA were significantly increased in patients with BC (30 cases), compared with those of patients with benign breast (10 cases) tumors and controls $(n=10)$.

Furthermore, Our results are in agreement with Iqbal et al., (2015) who confirmed that the ccfDII value was significantly higher in serum of BC patients (148 cases) compared to controls (51 healthy subjects).

VEGF is well established now as one of the key regulators of tumor angiogenesis. It is proved that breast cancers which express high VEGF levels are associated with greater angiogenesis and lymphangiogenesis that facilitate both LN and distant metastasis and so poor prognosis (Ali et al., 2011).

In our study; VEGF was higher in BBD and BC groups than control group with $\mathrm{P} 2$ and $\mathrm{P} 3<0.001$, but there was no statistical significant difference between BBD and BC ( $\mathrm{P} 4=0.455)$. Similar comparable high preoperative serum VEGF-A levels in benign breast diseases (968 - 6551 pg/ ml) were reported by Namagondlu and Shrivastava (2021).

Yamamoto et al., (1996) tested the serum VEGF among 137 BC patients, only $12(8.8 \%)$ revealed a relative increase in serum VEGF levels. This elevation was associated with progression of the disease and expression of tumor VEGF in tumor tissue. They concluded that VEGF is present in normal serum and its level increases in some of cancer patients.

These results are not in agreement with a study done by Ali et al., (2011) who found that the mean serum level of VEGF was significantly elevated in BC patients $(n=$ 120 ) before surgery when compared to that in patients with benign breast lesions $(n=30)$. This difference may be due to lower number of BC cases in our study and most of them were non metastatic $(81.4 \%)$.

Our results reported significant positive correlation of 
ccf DNA concentration with higher tumor grade. These results are in agreement with Iqbal et al., (2015) who confirmed that the ccf DII value in multivariate analysis showed a positive correlation with the tumor size and it could predict the overall survival at 5 years and diseasefree survival at 4 years. Updated meta-analysis done by Guo and Hua, 2021 to assess the diagnostic accuracy of ccfDNA in BC found that ccf DNA has a better diagnostic performance in patients with G3 than in patients with G1G2. Reasearchers explained this variability of ccf DNA levels in cancer patients according to tumor burden, stage, vascularity, cellular turnover, and response to therapy (Kohler et al., 2011). In the current study grade I and II constitute $67.4 \%$ so variations in tumor grading in different studies could explain these differences.

On the other hand; in this study; no significant correlation was found between ccfDNA, DNAII or VEGF serum levels with $\mathrm{BC}$ stage. This is not in agreement with a study done by El Edel et al., (2018) who reported significant statistical difference between the level of plasma ccf DNA and tumor staging $(\mathrm{P}=0.001)$. The level of ccf DNA was significantly higher in stage III when compared with stages I and II. Umetani et al., (2006) also, reported statistically significant increase in ccf DNA in patients with stages III and IV BC over patients with $\mathrm{BC}$ initial stages (I and II), and they attributed this rise to more corruption happening in late tumor phases than early phases.

In our study; most of $\mathrm{BC}$ cases were non metastatic (81.4\%) which may explain this difference. Also, Sobhani et al., (2018) suggested that DNA II value could increase at earlier stages of the $\mathrm{BC}$ and decrease in metastatic BC.

Comparing post radical mastectomy ccf DNA concentrations with basal median values in our research; revealed significant reduction of its median value after surgery. Similar results reported by Hassan et al., (2021) observed higher concentrations of ccf DNA in the pre-operative period (mean $\pm \mathrm{SD}: 439 \pm 190.4 \mathrm{ng} / \mathrm{ml}$ ) consistent with presence of tumor burden. Post-surgery, there was a drop in ccf DNA concentrations after removal of macroscopic tumor burden as evident by ccf DNA concentrations in the first 2 weeks following surgery (mean \pm SD: week 1-2, $410.6 \pm 160.5 \mathrm{ng} / \mathrm{ml}$ ).

Also; Catarino et al., (2008) reported statistically significant differences in ccfDNA levels in patients before and after BC surgery (105.2 vs. $59.0 \mathrm{ng} / \mathrm{mL}, \mathrm{p}=0.001)$.

To test the diagnostic performance of using cef DNA and DNA II as screening tools, we used ROC curve of cancer patients against both benign and control groups and found that the AUC of ROC curves were 0.860, 0.874; 0.727 and 0.836 respectively. Meanwhile, VEGF failed to discriminate ( $\mathrm{AUC}=0.545$ and 0.986 respectively). The optimal cut off value that could discriminate between BC and BBD were $74 \mathrm{ng} / \mathrm{ml}$ and 0.44 for each of ccf DNA and DNA II respectively with $90 \%$ specificity for both and 67.4, 51.2 \% sensitivity, 85.3, 81.5 \% PPV and 76.3, $68.2 \%$ NPV respectively.

Previous studies confirmed the high accuracy of ccf DNA levels in discriminating $\mathrm{BC}$ from benign lesion whatever the method used to handle the blood samples, purify and quantify plasma DNA, but they differed in the final concentrations. The study design including number of patient and controls, tumor grade and the type of blood samples had a significant impact on ccf DNA yields, as well as, the methods used to extract and quantify ccfDNA. All these factors make considerable variations between studies and difficulty to compare the values reported by different research groups (Xu and Liu, 2020).

Xu and Liu, (2020) reported basal optimal cut-off point $12.25 \mathrm{ng} / \mathrm{mL}$ for plasma ccf DNA in BC patients with sensitivity $79.12 \%$ and specificity $86.15 \%$ and the AUC was 0.865 . Tang et al. (2018) showed a lower sensitivity of $65.0 \%$ and a specificity of $70.0 \%$ for serum ccf DNA in $\mathrm{BC}$ patients.

In agreement with our results, Yu et al., (2019) meta-analysis of 13 studies found that ccf DNA had a high diagnostic value, in which the pooled sensitivity and specificity reached 87 and $87 \%$, respectively and the summary receiver operating characteristic (SROC) curve reached 0.93 in $\mathrm{BC}$ patients. This meta-analysis suggested that ccf DNA could be used as a screening tool for early detection of $\mathrm{BC}$.

Our results are in concordance with the results of El Edel et al., (2018); they reported that plasma ccf DNA was significantly increased in the breast cancer group when compared with that in both the benign and control groups ( $\mathrm{P}=0.001$ for both groups). ROC for ccf DNA showed that the sensitivity was $86.67 \%$, the specificity was $60.0 \%$, the positive predictive value was $82.1 \%$, and the negative predictive value was $60.0 \%$. A possible reason may be that the ccf DNA is discharged from cancer cells and is not found in the hyperplasia samples or in healthy controls.

A recent meta-analysis study done by Yan and his colleagues involving 11 publications; the association between ccf DNA and prognosis of $1336 \mathrm{BC}$ patients was estimated. They revealed that ccf DNA concentration, its mutation, and DNA integrity were significantly associated with outcome of $\mathrm{BC}$ patients. Compared with patients with mutation or high levels of ccf DNA, patients without mutation or with low levels of ccf DNA tend to have a favorable progression free survival (PFS) (Yan et al., 2018).

Our logistic regression analysis showed that ccf DNA concentration and DNA II were considered as predictors of BC development in both uni- and multivariate analyses.

The meta-analysis analyzed by Yan et al., (2018) reported that ccf DNA was a strong predictive for BC development. The subgroup analysis classified by tumor stage showed that ccf DNA was applicable to both early-stage and metastatic groups of BC patients.

Lin et al., (2017) performed another meta-analysis to calculate the overall accuracy of ccf DNA assays for detection of $\mathrm{BC}$ and they found that, the sensitivity and specificity of ccf DNA assays based on 24 primary studies were 0.70 and 0.87 respectively.

Buonoa et al., (2019) concluded that cell tumor DNA could be used to detect and characterize cancer at early stage and to monitor the genomic profile of tumors and detect any genetic alterations before clinical symptoms or radiological evidence of progression. As a result, ccf DNA analysis may guide clinical decision-making 
and through the integration with other solid and liquid biopsy techniques, will lead to a growingly cancer care personalization (Madhavan et al., 2014).

Madhavan et al., (2014) observed a more fragmented nature of ccf DNA or decreased ccf DNA II in BC cases compared to controls; they further demonstrated a hierarchical decrease of ccf DNA II and increase of ccf DNA concentration from cases with locally confined primary breast cancer $(\mathrm{PBC})$ to those with metastatic breast cancer (MBC) especially in patients with poorer prognosis.

Different results by qPCR for measuring DNA integrity could be due to different laboratory methods. Most of the authors, during their measurement of ccf DII through the ALU sequences, decided to use a standard DNA curve (Umetani et al., 2006) and used the fluorescein or ROX passive reference dyes to improve the quality of their results (Agostini et al., 2012; Iqbal et al., 2015). Additionally, the specificities of the amplification reactions for the different couple of primers used have been controlled by means of denaturation curves or gel electrophoresis (Sobhani et al., 2018).

Although ccf DNA concentration has been confirmed to be an independent biomarker in $\mathrm{BC}$ patients, the varied amount of ccf DNA concentration and the lack of specificity such as increased ccf DNA concentration observed in other cancers and benign diseases or under physiological conditions limited its potential clinical use as a single marker (Szpechcinski et al., 2015). Therefore, the combination of ccf DNA variables is critical (Sobhani et al., 2018). Yu et al., (2019) recommended the diagnostic efficiency of ccf DNA on breast cancer detection can be much improved in combination with other known biomarkers in $\mathrm{BC}$.

In conclusion, Circulating molecular markers in peripheral blood ("liquid biopsies") are of increasing importance because of their advantages such as easy accessibility, reproducibility and their ability for early detection of cancer. Ccf DNA and DNAII are promising markers in the diagnosis, prognosis, management and follow up of $\mathrm{BC}$ especially if combined with other traditional markers.

Further large-scaled, well-designed studies are required to confirm our findings, and to provide a basis for future clinical practice.

\section{Author Contribution Statement}

Rania Elhelaly: conceptualization, methodology, formal analysis, result interpretation, revision and publication. Narmen Effat: methodology. Mohamed Abd El-Fattah Hegazy: supervision and support to the recruitment of patients. Khalid Abd Elwahab: clinical evaluation and support to the recruitment of patients. Omar Hamdy: clinical evaluation and support to the recruitment of patients. Ekbal M. Abo-hashem: Project administration and funding acquisition, conceptualization and supervision. Rasha Elzehery: conceptualization, methodology, formal analysis, result interpretation and writing original draft. All authors were involved in critical revision and approved the final version of the manuscript before submission.

\section{Acknowledgement}

We thank all the staff responsible for this project in Mansoura University. Also we thank Mansoura Oncology Center nursing team for their help in sample collection. A great thank to all technicians and workers in Clinical pathology department who helped us in processing and storage of samples. Also we would thank all patients and healthy subjects for their contribution in this study.

\section{Funding statement}

This work was supported by a grant from Mansoura University.

\section{Ethical Committee}

The study protocol was approved by the research ethics committee of Mansoura University (code number: $\mathrm{R} / 17.04 .72$ ), and an informed written consent was obtained from each participant. It included an explanation of the study aim and design. All data was confidential.

\section{Data Availability Statement}

The data presented in this study are available on request from the corresponding author.

\section{Conflict of interest}

The authors declare that there is no conflict of interest regarding the publication of this paper.

\section{References}

Agostini M, Enzo MV, Bedin C, et al (2012). Circulating cellfree DNA: a promising marker of Regional lymph node metastasis in breast cancer patients. Cancer Biomark, 11, 89-98.

Ali EM, Sheta M, Abed El Mohsen M (2011). Elevated serum and tissue VEGF associated with poor outcome in breast cancer patients. Alexandria J Med, 47, 217-24.

Arko-Boham B, Aryee NA, Blay RM, et al (2019). Circulating cell-free DNA integrity as a diagnostic and prognostic marker for breast and prostate cancers. Cancer Genet, (235-236), 65-71.

Buonoa G, Gerratana L, Michela Bulfonid, et al (2019). Circulating tumor DNA analysis in breast cancer: Is it ready for prime-time?. Cancer Treat Rev, 73, 73-83.

Catarino R, Ferreira MM, Rodrigues H, et al (2008). Quantification of free circulating tumor DNA as a diagnostic marker for breast cancer. DNA Cell Biol, 27, 415-21.

Cheng X, Zhang L, Chen Y, Qing C (2017). Circulating cell-free DNA and circulating tumor cells, the "liquid biopsies" in ovarian cancer. J Ovarian Res, 10, 75.

Coppedè F, Lopomo A, Spisni R, Migliore L (2014). Genetic and epigenetic biomarkers for diagnosis, prognosis and treatment of colorectal cancer. World J Gastroenterol, 20, 943-56.

Corsetti V, Houssami N, Ghirardi M, et al (2011). Evidence of the effect of adjunct ultrasound screening in women with mammography negative dense breasts: interval breast cancers at 1 year follow up. Eur J Cancer, 47, 1021-6.

Crowley E, Di Nicolantonio F, Loupakis F, Bardelli A (2013). Liquid biopsy: monitoring cancer-genetics in the blood. Nat Rev Clin Oncol, 10, 472-84.

El Edel RH, El Gamaal AS, El Said HH, Noreldin RI, Omar 
MMM (2018). Cell-free DNA as a biomarker of breast cancer. Menoufia Med J, 31, 569-74.

Fleischhacker M, Schmidt B (2017). Circulating nucleic acids (CNAs) and cancer-a survey. Biochim Biophys Acta, 1775, 181-232.

Gilbert FJ, Tucker L, Young KC (2016). Digital breast tomosynthesis (DBT): a review of the evidence for use as a screening tool. Clin Radiol, 71, 141-50.

Gong B, Xue J, Yu J, et al (2012). Cell-free DNA in blood is a potential diagnostic biomarker of breast cancer. Oncol Lett, 3, 897-900.

Guerriero P, Moshiri F, Lupini L, et al (2019). Circulating tumor DNAs and non-coding RNAs as potential biomarkers for hepatocellular carcinoma diagnosis, prognosis and response to therapy. Hepatoma Res, 5, 6.

Guo Q, Hua Y (2021). The assessment of circulating cell-free DNA as a diagnostic tool for breast cancer: an updated systematic review and meta-analysis of quantitative and qualitative ssays. Clin Chem Lab Med, 59, 1479-500.

Hashad D, Sorour A, Ghazal A, Talaat I (2012). Free circulating tumor DNA as a diagnostic marker for breast cancer. J Clin Lab Anal, 26, 467- 72.

Hassan F, Wang JH, Cullinane C, et al (2021). Association of perioperative cell-free DNA (cfDNA) concentrations with risk of recurrence in patients with breast cancer. Res Square, DOI: https://doi.org/10.21203/rs.3.rs-1017958/v1.

He ZY, Li X, Chen QS, et al (2016). Elevated serum carcinoembryonic antigen and CA15 3 levels and the risk of site specific metastases in metastatic breast cancer. Transl Cancer Res, 5, 529-37.

International Agency for Research on Cancer, World Health Organization: Cancer Today/Population Fact Sheets: Egypt, Globocan 2020. Available at https://gco.iarc.fr/today/data/ factsheets/populations/818-egypt-fact-sheets.pdf.

Iqbal S, Vishnubhatla S, Raina V, et al (2015). Circulating cellfree DNA and its integrity as a prognostic marker for breast cancer. Springer Plus, 4, 265.

Lannin DR, Wang S (2017). Are small breast cancers good because they are small or small because they are good?. N Engl J Med, 376, 2286-91.

Lin Z, Neiswender J, Bin F, et al (2017). Value of circulating cell-free DNA analysis as a diagnostic tool for breast cancer: a meta-analysis. Oncotarget, 8, 26625-36.

Lo YM, Rainer TH, Chan LY, Hjelm NM, Cocks RA (2000). Plasma DNA as a prognostic marker in trauma patients. Clin Chem, 46, 319-23.

Madhavan D, Wallwiener M, Bents K, et al (2014). Plasma DNA integrity as a biomarker for primary and metastatic breast cancer and potential marker for early diagnosis. Breast Cancer Res Treat, 146, 163-74.

Namagondlu MK, Shrivastava RK (2021). Vascular endothelial growth factor-A (Vegf-A) As A prognostic marker in cases of carcinoma breast. Int J Surg Med, 7, 29-34.

Sobhani N, Generali D, Zanconati F, Bortul M, Scaggiante B (2018). Cell-free DNA integrity for the monitoring of breast cancer: Future perspectives?. World J Clin Oncol, 9, 26-32.

Stewart BW, Wild C (2014). International Agency for Research on Cancer, World Health Organization. World cancer report 2014. Lyon, Geneva: International Agency for Research on Cancer. WHO Press; 2014.

Szpechcinski A, Chorostowska-Wynimko J, Struniawski R, et al (2015). Cell-free DNA levels in plasma of patients with non-small-cell lung cancer and infammatory lung disease. Br J Cancer, 113, 476-83.

Tabár L, Vitak B, Chen THH, et al (2011). Swedish two county trial: impact of mammographic screening on breast cancer mortality during 3 decades. Radiology, 260, 658-63.
Tang Z, Li L, Shen L, et al (2018). Diagnostic value of serum concentration and integrity of circulating cell-free DNA in breast cancer: A Comparative Study With CEA and CA15-3. Lab Med, 49, 323-8.

Torre LA, Siegel RL, Ward EM, Jemal A (2016). Global cancer incidence and mortality rates and trends--An Update. Cancer Epidemiol Biomarkers Prev, 25, 16-27.

Umetani N, Giuliano AE, Hiramatsu SH, et al (2006). Prediction of breast tumor progression by integrity of free circulating DNA in serum. J Clin Oncol, 24, 23.

Umetani N, Hiramatsu S, Hoon DS (2006). Higher amount of free circulating DNA in serum than in plasma is not mainly caused by contaminated extraneous DNA during separation. Ann N Y Acad Sci U S A, 1075, 299-307.

VanderLaan PA, Yamaguchi N, Folch E, et al (2014). Success and failure rates of tumor genotyping techniques in routine pathological samples with non-small-cell lung cancer. Lung Cancer, 84, 39-44.

Wang R, Li X, Zhang H, Wang Ke, He J (2017). Cell-free circulating tumor DNA analysis for breast cancer and its clinical utilization as a biomarker. Oncotarget, 8, 75742-55.

$\mathrm{Xu} \mathrm{H}$, Liu G (2020). Diagnostic value of cfDNA and long fragment DNA in patients with breast cancer. Cell Mol Biol (Noisy-le-grand), 66, 186- 9.

Yamamoto Y, Toi M, Kondo S, et al (1996). Concentrations of vascular endothelial growth factor in the sera of normal controls and cancer patients. Clin Cancer Res, 2, 821-6.

Yan L, Chen Y, Zhou J, et al (2018). Diagnostic value of circulating cell-free DNA levels for hepatocellular carcinoma. Int J Infect Dis, 67, 92-7.

Yu D, Tong Y, Guo X, et al (2019). Diagnostic value of concentration of circulating cell-free DNA in breast cancer: A Meta-Analysis. Front Oncol, 9, 95.

Kohler C, Barekati Z, Radpour R, Zhong XY (2011). Cell-free DNA in the circulation as a potential cancer biomarker. Anticancer Res, 31, 2623-8.

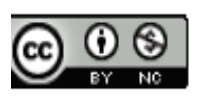

This work is licensed under a Creative Commons AttributionNon Commercial 4.0 International License. 